\title{
Benign Carotid Body Paraganglioma
}

National Cancer Institute

\section{Source}

National Cancer Institute. Benign Carotid Body Paraganglioma. NCI Thesaurus. Code C79950.

A carotid body paraganglioma that is confined to the site of origin, without metastatic potential. 